\title{
Isolation, Speciation and antifungal drug susceptibility of Candida species from clinically suspected infections in a tertiary care hospital
}

\author{
Gupta ${ }^{1}$, Shah $\mathbf{H}^{2}$ \\ ${ }^{1}$ Dr Jyoti Gupta, Assistant Professor, Department. of Microbiology, Chirayu Medical College \& Hospital, Bhopal, M.P., \\ ${ }^{2}$ Dr. Harshada Shah, Prof and Head, Department of Microbiology, R.D.Gardi Medical College, Surasa, Ujjain, M.P, India
}

Address for Correspondence: Dr Jyoti Gupta, Assistant Professor, Department of Microbiology, CMCH, Bhopal, Email ID: drjyoti93@gmail.com

\begin{abstract}
Introduction: The incidence of fungal infections has increased dramatically over the last two to three decades. Study was done on, Clinical samples from suspected patients of candidiasis. Study period was one and a half year from January 2013 to June 2014. Out of 915 clinically suspected samples of candidiaisis processed in the Microbiology Laboratory, $156(17.04 \%)$ yielded growth of Candida species. Methods: Candida was identified from Clinical samples by wet mount, Gram stain and Culture on SDA. The organisms were further speciated by germ tube test, Cornmeal agar Morphology, Sugar assimilation and Fermentation tests and CHROM agar. Antifungal susceptibility testing was done by disc diffusion method with Fluconazole $(25 \mu \mathrm{g})$, Amphotericin-B(100U), Itraconazole(10 $\mu \mathrm{g})$, Nystatin $(50 \mu \mathrm{g})$, Clotrimazole $(10 \mu \mathrm{g})$ and Voriconazole $(1 \mu \mathrm{g})$. Results: C.tropicalis (46.79\%) was the most common species isolated followed by C.albicans $(37.17 \%)$ and C.parapsilosis (9.61\%). Non albicans Candida species(NAC) (62.82\%) was more than C.albicans

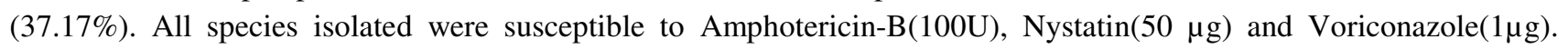
Resistance to commonly used antifungal agents was Fluconazole-20.40\%, Clotrimazole-18.26\% and Itraconazole$17.34 \%$. Conclusion: Species identification is important for treatment of Candida infections, as NAC species continue to be increasingly documented and not all species respond to same treatment.
\end{abstract}

Keywords: Candida albicans, Non albicans Candida, Candidiasis

\section{Introduction}

The incidence of fungal infections has increased dramatically over the last two to three decades [1,2]. Extensive and inappropriate use of antimicrobial agents as well as use of immunosuppressant drugs in various diseases has contributed to increased propensity for opportunistic fungal infections [3].

Candida species is the fifth most common nosocomial urinary pathogen in India [4]. Candidiasis is the fourth common cause of nosocomial bloodstream infections worldwide, accounting for $9 \%$ of all such infections in the United State [5]. As per CDC Guidelines for Sexually transmitted diseases an estimated $75 \%$ of women will have at least one episode of VVC, and $40 \%-45 \%$ will have two or more episodes[6]. Predisposing factors for Candidiasis are diabetes,

Manuscript received: $03^{\text {rd }}$ December 2016

Reviewed: $10^{\text {th }}$ December 2016

Author Corrected: $17^{\text {th }}$ December 2016

Accepted for Publication: $28^{\text {th }}$ December 2016 immunodeficiency, malignancy, increasing number of critically ill patients, surgical procedures, cytotoxic therapies with prolonged neutropenia, other immunosuppressive therapies, prolonged use of broadspectrum antibiotics, indwelling invasive medical devices and intensive care supports [7].

Although Candida albicans is the most prevalent species involved in both mucocutaneous and disseminated infections, the incidence of candidiasis due to non-albicans Candida (NAC) spp. is increasing. The clinical manifestations of infections caused by different members of NAC spp. are usually indistinguishable, but several NAC spp. are inherently resistant or acquire resistance, or both, to commonly used antifungal drugs [8]. Continuous monitoring of trends of species distribution and antifungal resistance pattern is essential to control and optimize therapy of Candida infection [9]. 


\section{Materials and methods}

Present study was carried out in the Department of Microbiology, Ruxmaniben Deepchand Gardi Medical college, Ujjain, MP. This is Hospital based cross sectional study for a period of one and a half year from January 2013 to June 2014. The study was approved by Institutional Ethics Committee. The samples (915) of the present study were received in Microbiology laboratory. Details of the patients were recorded.

\section{Inclusion criteria}

i) Clinically suspected patients of Candidiasis were included in study.

ii) Patient given consent for participation in study

\section{Exclusion Criteria}

i) Patients with history of receiving any antifungal drug 30 days prior to study.

ii)Those patients who were not willing to give the consent

All samples were collected under aseptic precautions from Clinically suspected patients of Candidiasis. Clinical samples where urine, blood, vaginal swab, oral swab, sputum, stool, lip scraping, pus, CSF, central line tip, eye swab and umbilical swab. Each sample was processed immediately on receipt in laboratory as per standard microbiological procedures [10]. All the samples were processed in the following manner.

\section{(A) Direct demonstration of fungal elements from clinical samples}

i) KOH wet mount : Wet film was examined for yeast cells, pseudohyphae and pus cells first under 10x and then 40x objectives.

ii) Gram stain: smear was stained by Gram's method and Observed under oil immersion objective for:

a) Gram positive , 4-8 $\mu \mathrm{m}$ budding yeast cells with or without pseudohyphae

b) Pus cells, c) Epithelial cells, d) Bacteria.

Defining criteria of candidiasis- Smear showing budding yeast cells, pseudohyphae and pus cells denoted infection by Candida species. But in case of C.glabrata presence of pus cells and yeast cells were indicative of infection. Isolation of the same yeast in significant numbers from multiple specimens from the same body site was used to prove yeast as a pathogen [11].

\section{B) Isolation of Candida in culture and species identification}

Culture- All specimens were inoculated onto Sabouraud's dextrose agar (SDA) with chloramphenicol (0.05gms/litre) and blood agar (HiMedia, Mumbai) and incubated at $37^{\circ} \mathrm{C}$ for $24-48 \mathrm{hrs}$. Colonies appeared within $1-3$ days as creamy white,smooth pasty with a yeasty odour. Candida isolates were identified by Gram staining.

\section{Criteria used to differentiate between infection and colonization for Candida species in various samples.}

1) Urine- Candiduria was diagnosed by urine culture. The urine samples were spread by calibrated loop (0.01 ml) as per standard protocol for urine culture. Plates were incubated aerobically at $37^{\circ} \mathrm{C}$ and read at 24 hours. In case of urine samples, colony counts are important to differentiate between colonization and infection. Quantitative culture with colony count of $>10^{5} \mathrm{cfu} / \mathrm{ml}$ of urine is associated with infection in patients without indwelling catheters and $>10^{3} \mathrm{cfu} / \mathrm{ml}$ for catheterized patients. Pyuria usually supports diagnosis of Candida infection. Low colony counts in presence of pyuria were considered significant. Repeat isolation in same patient was also considered significant. [8,12 \&13].

2) Sputum- Specimen was considered as acceptable when 25 or more polymorphonuclear leukocytes were seen per low power $(10 x)$ field with few $(<10)$ squamous epithelial cells. [14]

3) Blood- Candidemia was defined as the presence of at least one positive blood culture containing pure growth of Candida species with supportive clinical features [13].

4) Vaginal swab and Oral swab- 
The direct demonstration of pseudohyphae along with yeast cells is an important diagnostic feature.

5) CSF- Presence of yeast cells in the CSF with clinical features was considered significant [11].

\section{6) Central venous catheter tip}

Greater than 15 colony-forming units (CFU) on roll-plate culture was considered diagnostic of CRBSI.

\section{C) Tests for identification of Candida species}

i) Germ tube test [13]

ii) Cornmeal agar [11]

iii) Sugar fermentation tests $[8,13 \& 15]$

iv) Sugar assimilation tests [10]

v) Chrom agar [10]

vi) Tetrazolium reduction media [10]

1) Pagano Levin base (PBL) agar was prepared according to the manufacturer's instructions HiMedia, Mumbai. After autoclaving, PBL media was allowed to cool to $50^{\circ} \mathrm{C}$ and aseptically $5 \mathrm{ml}$ of $1 \% 2,3$, 5-triphenyltetrazolium chloride (TTC) solution was added and mixed well and then $5 \mathrm{ml}$ of rehydrated contents of 1vial of neomycin suspension was added and mixed well and poured into flat bottomed sterile petri-dishes on a level, approximately $4 \mathrm{~mm}$.

2) The yeast isolate to be tested was inoculated onPBL agar and incubated at $37{ }^{\circ} \mathrm{C}$ for $24-72$ hours.

Table-1: Colony characters on Tetrazolium reduction media

\begin{tabular}{|l|l|}
\hline Tetrazolium reduction media & Colony colors \\
\hline C. albicans & Pale pink \\
\hline C. tropicalis & Dark, maroon-red \\
\hline C.kefyr & Salmon pink \\
\hline C.krusei & White to pale pink (dry) \\
\hline C.parapsilosis & Rose pink \\
\hline C.guilliermondii & Pink pasty \\
\hline
\end{tabular}

D) Antifungal Susceptibility Testing (AFST) [16].

AFST was performed by Kirby-Bauer disc diffusion method as per CLSI USA guideline (M-44A2). Antifungal agents used for disc diffusion method are:

i) Amphotericin(100U), ii)Fluconazole $(25 \mu \mathrm{g})$, iii) Nystatin $(50 \mu \mathrm{g})$, iv)Itraconazole $(10 \mu \mathrm{g}), \mathrm{v})$ Clotrimazole $(10 \mu \mathrm{g})$, vi)Voriconazole $(1 \mu \mathrm{g})$

Media used- Mueller-Hinton Agar (HiMedia,Mumbai) supplemented with $2 \%$ Glucose and $0.5 \mu \mathrm{g} / \mathrm{ml}$ of Methylene blue Dye (GMB-MH). ATCC 90028 C.albicans was used as a Quality control.

Table-2: Interpretation of disc diffusion method $[16,17,18]$

\begin{tabular}{|l|c|c|c|c|}
\hline Drugs & Disc content $(\boldsymbol{\mu g})$ & $\mathbf{S}(\mathbf{m m})$ & SDD $(\mathbf{m m})$ & $\mathbf{R}(\mathbf{m m})$ \\
\hline Fluconazole & 25 & $\geq 17$ & $14-16$ & $\leq 13$ \\
\hline Amphotericin-B & 100 & $\geq 15$ & $13-14$ & $\leq 12$ \\
\hline Itraconazole & 10 & $\geq 17$ & $14-16$ & $\leq 13$ \\
\hline Nystatin & 50 & $\geq 17$ & $14-16$ & $\leq 13$ \\
\hline Clotrimazole & 10 & $\geq 17$ & $14-16$ & $\leq 13$ \\
\hline Voriconazole & 1 & $\geq 17$ & $14-16$ & $\leq 13$ \\
\hline
\end{tabular}

$\mathrm{S}=$ Sensitive,SDD=Susceptible dose dependant $\mathrm{R}=$ Resistant, 


\section{Results}

Table-3: Prevalence of Candida species in Patients samples (n=915)

\begin{tabular}{|l|c|c|c|c|}
\hline S.N. & Sample & Total no screened & Total No of isolates & \% \\
\hline 1 & Urine & 447 & 67 & 14.98 \\
\hline 2 & HVS & 95 & 23 & 24.21 \\
\hline 3 & Oral swab & 35 & 23 & 65.71 \\
\hline 4 & Sputum & 110 & 14 & 19.09 \\
\hline 5 & Blood & 200 & 2 & 7 \\
\hline 6 & Stool & 5 & 1 & 40 \\
\hline 7 & Pus & 4 & 1 & 25 \\
\hline 8 & Central line tip & 5 & 1 & 20 \\
\hline 9 & Lip scraping & 1 & 1 & 100 \\
\hline 10 & Umbilical swab & 5 & 1 & 20 \\
\hline 11 & Eye swab & 3 & $\mathbf{1 5 6}$ & 33.33 \\
\hline 12 & CSF & 5 & $\mathbf{9 1 5}$ & 20 \\
\hline
\end{tabular}

Majority of isolates were from urine, followed by vaginal swab and Oral swab.

Table-4: Age and gender wise distribution of patient's with Candida isolates $(n=156)$

\begin{tabular}{|c|c|c|c|}
\hline Age group & No of patients (\%) & Male (\%) & Female(\%) \\
\hline$<28$ days & $14(8.97)$ & $7(4.48)$ & $7(4.48)$ \\
\hline $1-10 y r$ & $11(7.05)$ & $04(2.56)$ & $7(4.48)$ \\
\hline $11-20 y r$ & $7(4.48)$ & $02(1.28)$ & $5(3.20)$ \\
\hline $21-30 y r$ & $40(25.64)$ & $12(7.69)$ & $28(17.94)$ \\
\hline $31-40 y r$ & $33(21.15)$ & $17(10.89)$ & $16(10.25)$ \\
\hline $41-50 y r$ & $22(14.10)$ & $12(7.69)$ & $12(7.69)$ \\
\hline $51-60 y r$ & $15(9.61)$ & $10(6.41)$ & $3(1.92)$ \\
\hline$>61 y r$ & $14(8.97)$ & $\mathbf{7 4 ( 4 7 . 4 3 )}$ & $4(2.56)$ \\
\hline Total & $\mathbf{1 5 6}$ & $\mathbf{8 2}(\mathbf{5 2 . 5 6})$ \\
\hline
\end{tabular}

Most patients from whom Candida species was isolated were females of 21-30yrs(25.64\%) age group.

Table-5: Distribution of Candida species $(n=156)$

\begin{tabular}{|c|c|c|}
\hline Candida species & No of isolates & Percentage (\%) \\
\hline C.tropicalis & 73 & 46.79 \\
\hline C.albicans & 58 & 9.61 \\
\hline C.parapsilosis & 15 & 1.92 \\
\hline C.guillermondii & 3 & 1.92 \\
\hline C.kefyr & 3 & 1.28 \\
\hline C.krusei & 2 & 1.28 \\
\hline C.dubliniensis & 2 & 100 \\
\hline Total & 156 & \\
\hline
\end{tabular}


C.tropicalis $(46.79 \%)$ was the most common species isolated followed by C.albicans (37.17\%) and C.parapsilosis $(9.61 \%)$.

Table-6: Distribution of C.albicans and NAC (n=156)

\begin{tabular}{|l|c|}
\hline Species & No of isolate (\%) \\
\hline Non- albicans candida spp. & $98(62.82 \%)$ \\
\hline C.albicans & $58(37.17 \%)$ \\
\hline Total & $\mathbf{1 5 6}$ \\
\hline
\end{tabular}

NAC $(62.82 \%)$ was more than C.albicans $(37.17 \%)$

Table-7: Distribution of different Candida species among various clinical samples ( $\mathbf{n = 1 5 6 )}$

\begin{tabular}{|c|c|c|c|c|c|c|c|c|}
\hline \multicolumn{2}{|c|}{$\begin{array}{c}\text { No of positive } \\
\text { Samples }(\%)\end{array}$} & $\begin{array}{c}\text { C.tropica } \\
\text { lis }\end{array}$ & $\begin{array}{c}\text { C.albican } \\
\text { s }\end{array}$ & $\begin{array}{c}\text { C.parapsilos } \\
\text { is }\end{array}$ & $\begin{array}{c}\text { C.guillermon } \\
\text { dii }\end{array}$ & $\begin{array}{c}\text { C.kefy } \\
\text { r }\end{array}$ & $\begin{array}{c}\text { C.krus } \\
\text { ei }\end{array}$ & $\begin{array}{c}\text { C.dubli } \\
\text { inensis }\end{array}$ \\
\hline Urine & $67(42.94)$ & 36 & 22 & 05 & 01 & 02 & 01 & 0 \\
\hline $\begin{array}{c}\text { Vaginal } \\
\text { Swab }\end{array}$ & $23(14.74)$ & 9 & 12 & 02 & 0 & 0 & 0 & 0 \\
\hline oral swab & $23(14.74)$ & 08 & 12 & 0 & 0 & 0 & 01 & 02 \\
\hline Sputum & $21(13.46)$ & 12 & 05 & 04 & 0 & 0 & 0 & 0 \\
\hline Blood & $14(8.97)$ & 7 & 2 & 03 & 02 & 0 & 0 & 0 \\
\hline Stool & $02(1.28)$ & 0 & 1 & 0 & 0 & 01 & 0 & 0 \\
\hline Pus & $01(0.6)$ & 01 & 0 & 0 & 0 & 0 & 0 & 0 \\
\hline $\begin{array}{c}\text { Central } \\
\text { line tip }\end{array}$ & $01(0.6)$ & 0 & 0 & 1 & 0 & 0 & 0 & 0 \\
\hline Eye swab & $01(0.6)$ & 0 & 01 & 0 & 0 & 0 & 0 & 0 \\
\hline CSF & $01(0.6)$ & 0 & 01 & 0 & 0 & 0 & 0 & 0 \\
\hline $\begin{array}{c}\text { Umbilical } \\
\text { Swab }\end{array}$ & $01(0.6)$ & 0 & 01 & 0 & 0 & 0 & 0 & 0 \\
\hline $\begin{array}{c}\text { Lip } \\
\text { scraping }\end{array}$ & $01(0.6)$ & 0 & 1 & 0 & 0 & 0 & 0 & 0 \\
\hline Total & $\mathbf{1 5 6}$ & $\mathbf{7 3}$ & $\mathbf{5 8}$ & $\mathbf{1 5}$ & $\mathbf{0 3}$ & $\mathbf{0 3}$ & $\mathbf{0 2}$ & $\mathbf{0 2}$ \\
\hline
\end{tabular}

The highest number of isolates was from Uine samples constituting 67 (42.94\%).

Non albicans Candida species was the common isolate in all clinical samples except vaginal and oral swab.

Table -8: Associated Predisposing conditions among patients of Candidiasis

\begin{tabular}{|l|c|c|}
\hline Predisposing conditions & No. of patients & Percentage (\%) \\
\hline Central venous catheter & 55 & 35.25 \\
\hline Diabetes mellitus & 37 & 23.71 \\
\hline Urinary Catheter & 32 & 15.38 \\
\hline HIV & 24 & 13.46 \\
\hline TB & 21 & 10.89 \\
\hline Pregnancy & 17 & 10.89 \\
\hline History of Major surgery & 17 & 10.25 \\
\hline History of chronic smoking & 16 & 8.33 \\
\hline Preterm \& LBW & 13 & 7.69 \\
\hline Steroid therapy & 12 & \\
\hline
\end{tabular}

Many patient's having multiple predisposing factors among Candidiasis. 


\section{Research Article}

For Voriconazole and nystatin ,no strains shows resistant,and $1.96 \%$ shows intermediate sensitivity. For Itraconazole, $82.05 \%$ were sensitive, $3.20 \%$ strains were intermediate and $14.74 \%$ strains were reistant. For Clotrimazole, $79.48 \%$ were sensitive,3.84\% strains were intermediate and $16.66 \%$ strains were reistant. For fluconazole, $78.20 \%$ were sensitive, $3.84 \%$ strains were intermediate and $17.94 \%$ strains were reistant.

Table-9: AFST by Disc Diffusion test

\begin{tabular}{|c|c|c|c|c|c|c|c|c|c|c|c|c|c|c|c|c|c|c|}
\hline \multirow[b]{2}{*}{ es } & \multicolumn{3}{|c|}{$\begin{array}{l}\text { Fluconazol } \\
\text { e } \\
\text { (FC) }\end{array}$} & \multicolumn{3}{|c|}{$\begin{array}{l}\text { Voriconazol } \\
\text { e (VCR) }\end{array}$} & \multicolumn{3}{|c|}{$\begin{array}{l}\text { Nystatin } \\
\text { (NYS) }\end{array}$} & \multicolumn{3}{|c|}{$\begin{array}{l}\text { Itraconazol } \\
\text { e } \\
\text { (ITR) }\end{array}$} & \multicolumn{3}{|c|}{$\begin{array}{l}\text { Clotrimazo } \\
\text { le } \\
\text { (CLOT) }\end{array}$} & \multicolumn{3}{|c|}{$\begin{array}{l}\text { Amphoterici } \\
\text { n-B (AMP- } \\
\text { B) }\end{array}$} \\
\hline & $\mathbf{S}$ & $\begin{array}{l}\text { S } \\
\text { D } \\
\text { D }\end{array}$ & $\mathbf{R}$ & $\mathbf{S}$ & $\begin{array}{l}\text { S } \\
\text { D } \\
\text { D }\end{array}$ & $\mathbf{R}$ & $\mathbf{S}$ & $\begin{array}{l}\text { S } \\
\text { D } \\
\text { D }\end{array}$ & $\mathbf{R}$ & $\mathbf{S}$ & $\begin{array}{l}\text { S } \\
\text { D } \\
\text { D }\end{array}$ & $\mathbf{R}$ & $\mathbf{S}$ & $\begin{array}{l}\text { S } \\
\text { D } \\
\text { D }\end{array}$ & $\mathbf{R}$ & $\mathbf{S}$ & $\begin{array}{l}\text { S } \\
\text { D } \\
\text { D }\end{array}$ & $\mathbf{R}$ \\
\hline C.tropicalis (73) & 58 & 3 & $\begin{array}{l}1 \\
2\end{array}$ & 72 & 1 & 0 & 73 & 0 & 0 & 61 & 2 & $\begin{array}{l}1 \\
0\end{array}$ & 60 & 2 & $\begin{array}{l}1 \\
1\end{array}$ & 73 & 0 & 0 \\
\hline C.albicans (58) & 48 & 2 & 8 & 58 & 0 & 0 & 58 & 0 & 0 & 50 & 2 & 6 & 49 & 1 & 8 & 58 & 0 & 0 \\
\hline C.parapsilosis (15) & 12 & 0 & 3 & 14 & 1 & 0 & 14 & 1 & 0 & 13 & 0 & 2 & 12 & 0 & 3 & 15 & 0 & 0 \\
\hline C.guillermondii (3) & 1 & 1 & 1 & 3 & 0 & 0 & 3 & 0 & 0 & 1 & 1 & 1 & 1 & 1 & 1 & 3 & 0 & 0 \\
\hline C.kefyr (3) & 2 & 0 & 1 & 3 & 0 & 0 & 2 & 1 & 0 & 2 & 0 & 1 & 2 & 1 & 0 & 3 & 0 & 0 \\
\hline C.krusei (2) & 0 & 0 & 2 & 1 & 1 & 0 & 1 & 1 & 0 & 0 & 0 & 2 & 0 & 0 & 2 & 2 & 0 & 0 \\
\hline C.dublienensis (2) & 1 & 0 & 1 & 2 & 0 & 0 & 2 & 0 & 0 & 1 & 0 & 1 & 0 & 1 & 1 & 2 & 0 & 0 \\
\hline Total (156) & $\begin{array}{l}12 \\
2\end{array}$ & 6 & $\begin{array}{l}2 \\
8\end{array}$ & $\begin{array}{l}15 \\
3\end{array}$ & 3 & 0 & $\begin{array}{l}15 \\
3\end{array}$ & 3 & 0 & 128 & 5 & $\begin{array}{l}2 \\
3\end{array}$ & $\begin{array}{l}12 \\
4\end{array}$ & 6 & $\begin{array}{l}2 \\
6\end{array}$ & $\begin{array}{l}15 \\
6\end{array}$ & 0 & 0 \\
\hline
\end{tabular}

All isolates were sensitive to Amphotericin-B.

\section{Discussion}

Among 915 suspected clinical samples received in Microbiology laboratory, 156 samples were positive for Candida species, so prevalence rate was $17.04 \%$. The prevalence rate by Rizvi et al,[19] Amar CS et al [15]and Feglo et al [20] study was $10.6 \%, 6.1 \%$, and $12.7 \%$ respectively. The prevalence rate was higher in present study (17.04\%) in comparison to Rizvi et al [19]. Amar CS et al [15]and Feglo et al[20]. However it was comparable to Roy et al[21] $(22.6 \%)$.

In the present study it was observed that Candidiasis can occur in all age group and in both sexes. In the present study, youngest study subject was a 1-day old while the oldest was 85 years old man. In the study by Kashid et al [22] the age range was from 1-day to 90 years.

The present study had a slight female preponderance with an overall male :female ratio $0.92: 1$. In north-east Indian study by Roy et al [21] it was observed that, the frequency of Candidiasis is more among females (51/113) as compared to males (41/113), but statistically by Chi square test, it has been seen that the incidence of Candida species distribution is independent on sex. Our study results matched with Roy et al [21].

In a study by Dalal PJ and Kelkar S, it was observed that vulvovaginitis was common in the sexually active age group of 21-40 years [23]. In the present study, vulvovaginitis was commonly seen in the same age group. 
Indian scenario- Studies reporting C. tropicalis as major isolates are Patel et al[2] Gujrat 2012,Sachin et al2014[9] Kashid et al[22]Bangalore 2011, Binesh et al[24]Tamil Nadu 2011. C.tropicalis (46.79\%) was the most common pathogen causing infection in present study also.

Our study showed that NAC Species were isolated at a higher rate $(62.82 \%)$ than C. albicans $(37.17 \%)$. These findings seem to suggest that NAC are emerging as important pathogens. Other NAC species in present study were Candida parapsilosis, Candida krusei and Candida guilliermondii. Amar C,[15] Jayalakshmi L[18] Vijaya D et.al,[25] Shivanand et al[26] and 2014 found $\mathrm{C}$. albicans as a common isolate, which does not correlate with the present study.

The rise in frequency of infection of non-albicans Candida species has been also observed in tertiary care centres in India, with the isolation rate ranging from $50 \%$ to $96 \%$.[21].

In this study the results of Chrom agar were exactly paralleled to that of Conventional method.

Association of species and underlying predisposing conditions- The risk factors were noted. In the present study major risk factor for Candidemia was use of intravascular catheters which act as a portal of entry for fungal infection and a significant cause of Candidemia. $2^{\text {nd }}$ most risk factors were Diabetes, followed by use of Urinary catheter, History of Broad spectrum antibiotics, HIV, Tuberculosis, Pregnancy, History of Major Surgery such as Laprotomy, Smoking, Preterm and Low birth weight baby and Steroid therapy). In many situations multiple predisposing factors were responsible for infection. For Example TB and HIV both were risk factors in 12 patients.

\section{AFST was done for 156 isolates with}

i) Amphotericin,Fluconazole, Nystatin, Itraconazole,Clotrimazole and Voriconazole

The in vitro susceptibility testing of antifungal agents is becoming increasingly important for in assessing empirical treatment recommendation.

No resistance detected in the isolates to amphotericin-B, nystatin and voriconazole in the present study. Rizvi et al [19] also reported same finding, no resistance to amphotericin-B, nystatin and voriconazole. Our findings correlated well with those in the studies by Kashid et al[22], Vijaya D et al[25] and Roy et al[21]. In these studies, C.albicans and NCA showed $100 \%$ sensitivity to amphotericin B while azole group of drugs were used as second choice. In our study Resistance was more in NAC as compared to C. albicans species. Similar finding was noted by Sachin et al [9].

Table-10: Resistance to Fluconazole in different studies

\begin{tabular}{|l|c|c|}
\hline Species & C.albicans (58) & Non albicans Candida spp (98) \\
\hline Present study & $13.79 \%$ & $20.40 \%$ \\
\hline Pahava etal[27] Indore 2014 & $2 \%$ & $3.9 \%$ \\
\hline $\begin{array}{l}\text { Roy et al[21] Northeast study Chhattisgarh } \\
2013\end{array}$ & $12 \%$ & $24 \%$ \\
\hline Patel et al[2] Gujrat 2012 & $25.5 \%$ & $57.62 \%$ \\
\hline Kashid et al[22] Banglore 2011 & 18.60 & 35.57 \\
\hline Shivanand et al[26] Karnataka 2011 & $22 \%$ & $25 \%$ \\
\hline
\end{tabular}

In the present study the Non albicans Candida spp showed $20.40 \%$ resistance to azole group of drugs and C. albicans isolates showed $13.79 \%$ resistance to azole group of drugs. Also the finding was correlated with those of a study done by Shivanand et al[26] in which NAC shows $25 \%$ resistance to fluconazole. In our study resistance for fluconazole by C. krusei was $100 \%$, This was also confirmed b Amar C S et al [15] and Roy et al [21] who reported that all isolates of Candida krusei tested were resistance to fluconazole.

It is well established that Candida krusei is intrinsically resistant to fluconazole. In the current study, amphotericin B was the most effective antifungal agent. Western data have shown that Candida species are reliably susceptible to polyenes, azole and echinocandins. In India, amphotericin B is the drug of choice for invasive Candidiasis with low or no resistance reports. 
There are various reports from our country showing increasing trend towards fluconazole resistance especially among NAC Species which warrants its judicious use as a prophylactic agent in hospitals.

It is important for both Clinicians and Microbiologists. Hence, it is necessary to identify the complete clinical response to the given treatment, for which adequate information regarding the change in distribution of Candida species and their antifungal susceptibility pattern will be beneficial.

\section{Conclusion}

There was predominance of female patients $(52.56 \%$ versus 47.43 ) of age group of 21-30yrs (25.64\%). Out of 156 isolates, majority of them were from urine

(42.94\%) followed by vaginal swab and oral swab $(14.74 \%$ each). NAC outnumbered C.albicans. Prevalence of Candida was found to be higher in patients associated with predisposing factors.

This study provides data about distribution of various Candida species and their antifungal drug susceptibility among patients visiting our tertiary care hospital and our geographical area especially in and around Ujjain district (M.P.).

Funding: Nil, Conflict of interest: None initiated, Permission from IRB: Yes

\section{References}

1. Yigit N, Aktas A, Ayyildiz A. Detection of Coagulase Activity in Pathogenic Candida Species. J Int Med Res. 2008 Nov-Dec;36(6):1378-82.

2. Patel, L., Pethani, J., Bhatia, P., Rathod, S., Shah, P. Prevalence of Candida Infection and its Antifungal Susceptibility Pattern in tertiary Care Hospital, Ahmedabad. Nat J Med Res. 2012; 2(4): 439-41.

3. Singh, T., Kashyap, A., Ahluwalia, G. et al. Epidemiology of fungal infections in critical care setting of a tertiary care teaching hospital in North India: a prospective surveillance study. J Clin Sci Res. 2014;3: 14-25.

4. Prasad KN, Agarwal J, Dixit AK et al. Role of yeasts as nosocomial pathogens \& their susceptibility to fluconazole \& amphotericin B. Indian J Med Res. 1999 Jul;110:11-7.

5. Paswan, A., Dinesh, C., Singh, D et al. Isolation and distribution of candida species among different clinical situations in critically ill patients: prospective study. International Journal of Biomedical Research.

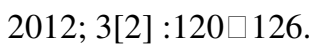

6. Chen XS, Yin YP, Liang GJ, Gong XD, Li HS, Shi $\mathrm{MQ}, \mathrm{Yu}$ YH. Co-infection with genital gonorrhoea and genital chlamydia in female sex workers in Yunnan, China. Int J STD AIDS. 2006 May;17(5):329-32.

7. Topley and Wilson's Microbiology and Microbial infections, Medical mycology. Chapter 30,Candidiasis, 579-620.

8. Deorukhkar SC, Saini S, Mathew S. Non-albicans Candida Infection: An Emerging Threat. Interdiscip Perspect Infect Dis. 2014;2014:615958. doi: 10.1155/2014/615958. Epub 2014 Oct 22.

9. Deorukhkar, S. C.; Saini, S. Species Distribution and Antifungal Susceptibility Profile of Candida Isolated from Various Clinical Specimens. Med Rev. 2014; 6(3) $: 11-15$.

10. Chander J. Textbook of Medical Mycology, $3^{\text {rd }}$ ed . Mehta publishers: 2012.

11. Fran Fisher and Norma B.Cook. Fundamentals of Diagnostic Mycology 1998; W.B. Saunders, Philadelphia. Pg 196-212.

12. Kashid, R., Sandhya, B., et al. Incidence of noncandida albicans in patients with urinary tract infection with special reference to speciation and antifungal susceptibility. J. of Evolution of Medical and Dental Sciences. 2012; 4(1): 577

13. Deorukhkar, S., Saini, S. Laboratory approach for diagnosis of Candidiasis through ages. Int.J.Curr.Microbiol ,App.Sci . 2014; 3(1): 206-218 .

14. Jha BJ, Dey S, Tamang MD, Joshy ME, Shivananda PG, Brahmadatan KN. Characterization of Candida species isolated from cases of lower respiratory tract infection. Kathmandu Univ Med J (KUMJ). 2006 JulSep;4(3):290-4.

15. Amar, C., Hajare, V. et al. Prevalence and antifungal susceptibility of Candida Species Isolated 


\section{Research Article}

from Patients Attending Tertiary Care Hospital. IOSRJDMS. 2014; 13(5): $44-49$.

16. Clinical and laboratory Standards Institute (CLSI), August 2009. Method for antifungal disk diffusion susceptibility testing of Yeasts. Approved guideline-2nd ed. CLSI document-M44-A2, 29(17).

17. Wayne PA et al,2004 Method for Antifungal Disc Diffusion Susceptibility Testing of Yeasts, CLSI M44A

18. Jayalakshmi, L., RatnaKumari.G., et al. Isolation, Speciation and Antifungal Susceptibility Testing of Candida from Clinical Specimens at a Tertiary Care Hospital Sch. J. App. Med. Sci. 2014; 2(6):3193-3198.

19. Rizvi, M.W., Malik A., Shahid, M., Singhal, S. Candida albicans infections in a north Indian tertiary care hospital, antifungal resistance pattern and role of SDS-PAGE for characterization. Biology and Medicine. 2011;3(2):176-181

20. Feglo P. K., Narkwa P. Prevalence and Antifungal Susceptibility Patterns of Yeast Isolates at the Komfo Anokye Teaching Hospital (KATH), Kumasi, British Microbiol Res J. 2012.2(1): 10-22

21. Roy R., et al. Trend of Candida infection and antifungal resistance in a tertiary care hospital of north east India. African J. of Microbiol Res. June 2013;Vol. 7(24): 3112-16.

22. Kashid A.R., Belawadi S., Devi G. Characterization and antifungal susceptibility testing for Candida species in a tertiary care hospital. J.Health Sci. Res. 2011; 2(2):1-7.

23. Dalal P. J., Kelkar S.S. Clinical patterns of Candida infections in Bombay. Indian J Dermat Venerol Leprosy 1980; 46(1): 31-2.

24. Lal Binesh., Y Kalyani M., et al. Phenotypic Characterization of Candida species and their antifungal susceptibility from a tertiary care centre Tamil Nadu JPBMS ., 2011; 11 (12):1-5

25. Vijaya D., Harsha T.R., Nagaratnamma, T. Candida speciation using chrom agar. J Clin and Diagnostic Res. 2011; 5: 755-757.

26. Shivanand D., Dominic, S. Species identification of Candida isolates in various clinical specimens with their antifungal susceptibility patterns. $\mathbf{J}$ of clinical and diagnostic research. $2011 ; 5(6): 1177-81$

27. Pahwa N, Kumar R, Nirkhiwale S, Bandi A. Species distribution and drug susceptibility of candida in clinical isolates from a tertiary care centre at Indore. Indian J Med Microbiol. 2014 Jan-Mar;32(1):44-8. doi: 10.4103/0255-0857.124300.

\section{How to cite this article?}

Gupta J, Shah H. Isolation, Speciation and antifungal drug susceptibility of Candida species from clinically suspected infections in a tertiary care hospital. Trop J Path Micro 2016;2(3):183-191.doi: 10.17511/jopm.2016.i03.18 